\title{
Efficient expansion and dopaminergic differentiation of human fetal ventral midbrain neural stem cells by midbrain morphogens
}

Diogo Ribeiro ${ }^{1}$, Rocio Laguna Goya ${ }^{2}$, Geeta Ravindran ${ }^{1}$, Romina Vuono ${ }^{2}$, Clare L. Parish $^{1,3}$, Claire Foldi ${ }^{1}$, Tobias Piroth ${ }^{4}$, Shanzheng Yang ${ }^{1}$, Malin Parmar ${ }^{5}$, Guido Nikkhah $^{4}$, Jens Hjerling-Leffler ${ }^{1}$, Olle Lindvall ${ }^{6}$, Roger A. Barker ${ }^{2}$ and Ernest Arenas ${ }^{1} \#$

${ }^{1}$ Laboratory of Molecular Neurobiology, Department of Medical Biochemistry and Biophysics, Karolinska Institute, 17177 Stockholm, Sweden.

${ }^{2}$ Cambridge Centre for Brain Repair, University of Cambridge, Forvie Site, Robinson Way, Cambridge CB2 OPY, United Kingdom.

${ }^{3}$ Current address: Florey Neuroscience Institute, The University of Melbourne, Parkville, Victoria, Australia.

${ }^{4}$ Laboratory of Molecular Neurosurgery and Neurological Clinic, Department of Stereotactical Neurosurgery, University Freiburg Medical Center, Breisacher Str. 64, 79106 Freiburg i. B., Germany.

${ }^{5}$ Department of Experimental Medical Science, Wallenberg Neuroscience Center and Lund Stem Cell Center, Lund University, BMC A11, 22184 Lund, Sweden.

${ }^{6}$ Laboratory of Neurogenesis and Cell Therapy, Wallenberg Neuroscience Center and Lund Stem Cell Center, University Hospital, SE-221 84 Lund, Sweden. 
\# Correspondence should be addressed to:

Ernest Arenas, MD, PhD

Laboratory of Molecular Neurobiology

Dept. Medical Biochemistry \& Biophysics

Karolinska Institute, S-171 77, Stockholm Sweden

Tel: ${ }^{+} 46-8-52487663$, Fax: ${ }^{+} 46-8-341960$

E-mail: ernest.arenas@ki.se

Running title: Expansion and differentiation of Human Fetal Midbrain dopaminergic neurons

Keywords: dopaminergic, human fetal ventral midbrain

Author contribution: DR: conception and design, collection and/or assembly of data, data analyses and interpretation, manuscript writing; RLG: collection and/or assembly of data, data analyses and interpretation; GR: collection and/or assembly of data, data analyses and interpretation; RV: collection and/or assembly of data; CLP: conception and design, collection and/or assembly of data, data analyses and interpretation; CF: collection and/or assembly of data; TP: collection and/or assembly of data; MP: collection and/or assembly of data; GN: conception and design; JH-L: conception and design; OL: conception and design; RAB: conception and design; EA: conception and design, fund raising, data analyses and interpretation, manuscript writing, final approval of manuscript. 


\section{ABSTRACT:}

Human fetal midbrain tissue grafting has provided proof-of-concept for dopamine cell replacement therapy (CRT) in Parkinson's disease (PD). However, limited tissue availability has hindered the development and widespread use of this experimental therapy. Here we present a method for generating large numbers of midbrain dopaminergic (DA) neurons based on expanding and differentiating neural stem/progenitor cells present in the human ventral midbrain (hVM) tissue. Our results show that hVM neurospheres (hVMN) with low cell numbers, unlike their rodent counterparts, expand the total number of cells 3-fold, whilst retaining their capacity to differentiate into midbrain DA neurons. Moreover, Wnt5a promoted DA differentiation of expanded cells resulting in improved morphological maturation, midbrain DA marker expression, DA release and electrophysiological properties. This method results in cell preparations that, after expansion and differentiation, can contain 6-fold more midbrain DA neurons than the starting VM preparation. Thus, our results provide evidence that by improving expansion and differentiation of progenitors present in the $\mathrm{hVM}$ it is possible to greatly enrich cell preparations for DA neurons. This method could substantially reduce the amount of human fetal midbrain tissue necessary for CRT in patients with PD, which could have major implications for the widespread adoption of this approach. 


\section{INTRODUCTION}

Parkinson's disease (PD) is a neurodegenerative disorder characterized by resting tremor, rigidity and slowness of movement (hypokinesia). The motor features of PD are due in part to the progressive loss of dopaminergic (DA) neurons in the substantia nigra pars compacta (SNpc), which project to the striatum and are involved in motor control. One promising therapeutic approach is cell-replacement therapy (CRT), in which DA neurons and/or precursors are grafted into the striatum in order to restore the lost nigrostriatal DA neurotransmission. Several cell types have been considered as potential sources of DA neurons, such as embryonic stem (ES) cells and induced pluripotent stem (iPS) cells which, due to their capacity to expand and differentiate, can generate large numbers of DA neurons and induce behavioral improvement in animal models of PD (Barberi, et al., 2003, Hargus, et al., 2010, Kawasaki, et al., 2000, Kim, et al., 2002, Kirks et al., 2012; Lee, et al., 2000, Sanchez-Pernaute et al., 2008; Wernig, et al., 2008). However, the lack of purity of the differentiated cultures, the risk of excessive proliferation and teratoma formation, as well as the poor survival of human ES cellderived DA cells after transplantation in animal models have so far prevented their use in clinical trials (Roy, et al., 2006, Sonntag, et al., 2007). In the past, human fetal ventral midbrain (VM) tissue has been used as a cell source for CRT, as these cells are correctly specified in vivo, pose no risk of tumor/teratoma formation and have been used in clinical trials to provide proof-of-principle that DA neurons derived from fetal human VM tissue can survive and offer significant benefits in patients (Kordower, et al., 1995, Mendez, et al., 2005, Piccini, et al., 1999, Politis et al 2010). However, several issues such as tissue availability, quality, standardization and the need for a high number of fetuses (6 to 7$)$ to treat one PD patient make this strategy impractical and unlikely to become a competitive therapeutic option (Bjorklund, et al., 2003, Freed, et al., 2001, 
Olanow, et al., 2003, Winkler, et al., 2005). Previous studies have shown that human ventral midbrain-derived cells can be propagated with mitogens (Hovakimyan, et al., 2006, Jin, et al., 2005, Maciaczyk, et al., 2008, Milosevic, et al., 2006, SanchezPernaute, et al., 2001, Storch, et al., 2001, Wang, et al., 2004). In these studies cells were typically expanded in the presence of epidermal growth factor (EGF) and basic fibroblast growth factor 2 (bFGF) (Hovakimyan, et al., 2006, Sanchez-Pernaute, et al., 2001, Storch, et al., 2001) and differentiated by removal of mitogens and addition of neurotrophins such as brain derived neurotrophic factor (BDNF) (Maciaczyk, et al., 2008) and glial cell-line derived neurotrophic factor (GDNF) (Jin, et al., 2005, Storch, et al., 2001), ascorbic acid, cyclic adenosine monophosphate (cAMP) (SanchezPernaute, et al., 2001) or cytokines (Jin, et al., 2005, Storch, et al., 2001). Immortalized human mesencephalic cell lines have also been established (Donato, et al., 2007, Lotharius, et al., 2002, Villa, et al., 2009), however DA neurons could only be generated and maintained after stable overexpression of $\mathrm{Bcl}-\mathrm{X}_{\mathrm{L}}$, an anti-apoptotic gene (Courtois, et al., 2010). Surprisingly, none of the studies up to date have examined the use of region-specific developmentally appropriate morphogens for the expansion and differentiation of hVM cells.

Morphogens are secreted factors that form gradients and play a prominent role in development by providing regional and cellular identity to cells in the neural tube. The most important morphogens for midbrain development are Sonic Hedhehog (Shh, a ventralizing signal), Fibroblast growth factor 8 (Fgf8, that provides the midbrainhindbrain identity), and Wnt5a (which regulates cell orientation and differentiation, reviewed in Inestrosa and Arenas, 2010). Interestingly, we have previously shown that mouse and rat VM neural stem cells can be propagated as neurospheres (VMN) and differentiated in the presence of Shh, FGF8 and Wnt5a. In these conditions, VMNs gave 
rise to a large number of functional DA neurons that were able to survive, integrate and induce functional recovery after transplantation in animal models of Parkinson's disease (Parish, et al., 2008). However, much less is known about the capacity of human endogenous VM progenitors to respond to morphogens and give rise to human DA neurons in vitro. Here, we examined whether VM morphogens, such as Shh, FGF8 and Wnt5a, can be applied to human VM neural stem cells, in order to improve the yield of DA neurons derived from human fetal midbrain tissue. Our results show that hVMN can be cultured as spheres and that the total number of cells can be expanded 3 fold over a 2-3 week period. Furthermore these VMN-expanded cells maintain the same DA differentiation potential after each passage and addition of Wnt5a increases the number of DA neurons per field by 3.3-fold, compared to controls. These increases together (total cells and $\mathrm{TH}$ cell density) resulted in 6 -fold increase in the $\% \mathrm{TH}^{+}$cells/Hoechst and total $\mathrm{TH}^{+}$cells obtained from one VM. Moreover, morphogen treatment maintained or increased the expression of typical midbrain markers such as TH, Nurr1, Foxa2, Lmx 1a and Lmx1b, compared to non-expanded hVM tissue. In particular, we found that Wnt5a increased the morphological and molecular differentiation of VMN cells into midbrain DA neurons, as well as their functionality, as assessed by DA release and electrophysiological properties. In summary, our results show that morphogen-treated human neural stem/progenitor cells gives rise to a 6-fold increase in the number of DA neurons compared to the starting VM preparation. Hence, the use of developmentally relevant midbrain factors for the expansion and differentiation of hVM cells may significantly reduce the need for multiple donor fetuses for grafting individual PD patients, thereby increasing the feasibility and accessibility of this technology in the future development of CRT for Parkinson's disease. 


\section{MATERIALS AND METHODS}

\section{hVM tissue}

Human fetal ventral mesencephalic tissue was collected and experiments performed at the Centre for Brain Repair (University of Cambridge), Freiburg University Medical Center and Wallenberg Neuroscience Center (Lund University). All fetuses were collected from routine termination of pregnancies under full ethical approval in line with the United Kingdom's Department of Health guidelines and local ethical approval (Local Research Ethics Committee, reference nr. 96/085), the local ethical committee of the University of Freiburg meeting the regulations of the German law (research project nr. 96/03) and the Swedish National Board of Health and Welfare (Socialstyrelsen, Dnr. 23 11667/2008 and Dnr. 23 2981/2009).

\section{hVMN cultures}

The VM was dissected from fetuses at post-conception (PC) week 6-11. VM tissues were dissociated in serum-free N2 medium supplemented with BDNF (30 ng/ml, R\&D) using collagenase/dispase $(700 \mu \mathrm{g} / \mathrm{ml}$; Roche) with agitation on an orbital mixer incubator ( $80 \mathrm{rpm}, 30$ minutes) followed by mechanical dissociation by gently pipetting through $200 \mu \mathrm{l}$ pipettes or flame-narrowed Pasteur pipettes. For proliferation, 2/3 of the cells from the dissociated tissue were plated at a final density of 150,000 cells $/ \mathrm{cm}^{2}$ on non-coated or non-adherent tissue culture plates in serum-free N2 medium (1:1 mixture of F12 and MEM, $15 \mathrm{mM}$ HEPES buffer, $1 \mathrm{mM}$ glutamine, $6 \mathrm{mg} / \mathrm{ml}$ glucose (SigmaAldrich), $3 \mathrm{mg} / \mathrm{ml}$ Albumax, and $\mathrm{N} 2$ supplement, all purchased from Invitrogen) supplemented with Shh (100 ng/ml), FGF8 (100ng/ml), BDNF (30ng/ml) and bFGF 
(20ng/ml), all purchased from R\&D. These cultures were referred to as passage 0 (P0). For differentiation, $1 / 3$ of the cells were plated onto poly-ornithine $(15 \mu \mathrm{g} / \mathrm{ml}$, SigmaAldrich) and laminin-coated 48 well plates (10 $\mu \mathrm{g} / \mathrm{ml}$, Trevigen) and left to differentiate for 4-14 days in N2 medium supplemented with BDNF (20 ng/ml, R\&D), GDNF (10 ng/ml, R\&D), TGF3 $\beta$ (1 ng/ml, R\&D), ascorbic acid (2mM, Sigma-Aldrich) and dibutyryl cAMP (1mM, Sigma-Aldrich) and Wnt5a (100 ng/ml, R\&D) or the equivalent volume of $0.1 \%$ bovine serum albumin (BSA) as a control for Wnt5a treatment. These cultures were referred to as differentiation 0 (D0). Cells in proliferation grew as spheres and were supplemented with fresh medium every 3 days. After 7 days of proliferation, half of the spheres were passaged using collagenase/dispase and half were plated for differentiation using the same conditions as described above; these cultures were referred to as passage 1 (P1) and differentiation 1 (D1), respectively. After 14 days of proliferation, the remaining spheres (referred to as passage 2, P2) were plated for differentiation (referred to as differentiation 2, D2).

\section{Immunocytochemistry}

Cultures were fixed in $4 \%$ paraformaldehyde for 20 minutes, washed three times with PBS and pre-incubated for 1 hour in blocking solution (PBS, 0.25\% Triton-X 100 and $5 \%$ normal goat serum) followed by incubation at $4{ }^{\circ} \mathrm{C}$ overnight with one or more of the following primary antibodies diluted in blocking solution: rabbit anti-tyrosine hydroxylase (TH, 1:300, PelFreeze), mouse anti- $\beta$ III tubulin (Tuj1;1:1000, Promega, Abcam), mouse anti-TH (1:200 Immunostar), Goat anti-Lmx1a (1:200 Santa Cruz), Goat anti-Nurr1 (1:200, R\&D). After washing, cultures were incubated for 1 hour at room temperature with the appropriate fluorophore conjugated secondary antibodies 
(1:700, AlexaFluor 555, 647 and 488). All cultures were counterstained with Hoechst 33258 for 10 minutes (1:1000, Invitrogen) to enable visualization of all nuclei.

\section{RT-PCR analysis}

Cells were lysed and total RNA was extracted using the RNeasy Mini Kit (Qiagen), 1 $\mu \mathrm{g}$ was treated with RQ1 RNase-free DNase (Promega, Madison, WI) and reverse transcribed using SuperScript II Reverse Transcriptase (Invitrogen) and random primers (Invitrogen) $\left(\mathrm{RT}^{+}\right.$reaction). Parallel reactions without the reverse transcriptase enzyme were done as a control ( $\mathrm{RT}^{-}$reaction). PCR conditions and Sybr green real-time quantitative PCR assays were performed as previously described (Rawal, et al., 2006). Expression levels were obtained by normalization with the value of the housekeeping gene encoding 18S rRNA (Ambion, Austin, USA) obtained for every sample in parallel assays. Fold changes were determined using the delta-delta CT method. The primer sequences were as follows:

hl8S (forward): GCCTTTGCCATCACTGCCATT,

h18S (reverse): GCCAGTGGTCTTGGTGTGCT;

hSOX2 (forward): GGGAAATGGGAGGGGTGCAAAAGAGG,

hSOX2 (reverse): TTGCGTGAGTGTGGATGGGATTGGTG;

hNESTIN (forward): CAGGAGCGGCTGCGGGCTACTGAAAAGTTCC, hNESTIN (reverse): CAGGGCTGAGGGGTGGTGCCAAGGAGG;

hGFAP (forward): CTCAAGAGGAACATCGTGGTAAAG, 
hGFAP (reverse): TCCTGCTTCGAGTCCTTAATGAC;

hßIII-TUBULIN (forward): GCCTCTTCTCACAAGTACGTGCCTCG,

hPIII-TUBULIN (reverse): GGGGCGAAGCCGGGCATGAACAAGTGCAG;

hLMXIB (forward): GGCACGAGGAGTGTTTGCAGT,

$h L M X 1 B$ (reverse): GTTTGCAGTACAGTTTCCGATCC;

hLMXIA (forward): CAGGGAAAGGAACTGCTGAG,

hLMXIA (reverse): CTGGTTTTGGAACCACACCT;

hFOXA2 (forward): GACTCCAGCCTCCTCAACTG,

hFOXA2 (reverse): CGAGGAGGACATGAGGTTGT;

$h T H$ (forward): GAGGGGAAGGCCGTGCTAAA,

$h T H$ (reverse): GAGGCGCACGAAGTACTCCA;

hNURR1 (forward): CAGCTCCGATTTCTTAACTCCAG;

hNURR1 (reverse): GGTGAGGTCCATGCTAAACTTGA.

\section{Cell Counts and Statistical Analyses}

The relationship between variables (initial number of cells, cell numbers at P2 and embryo age) was determined by linear regression. For $\mathrm{TH}^{+}$cells/field, $\mathrm{TH}^{+}$cells were counted in 8-10 random fields covered by Tuj $1^{+}$cells in three 48 -well plate wells per condition (differentiation round, D0-D2 and/or Wnt5a treatment). Counts were done using a 25x magnification eye piece with an eye grid and a 20x objective. Each field 
was determined by the eye grid, which corresponded to an area of $0,39 \mathrm{~mm}^{2}$ at $20 \mathrm{x}$ magnification. Cell numbers were averaged for each condition and compared using a Student's t-test. The $\% \mathrm{TH}^{+}$cells/Hoechst was calculated using the number of $\mathrm{TH}^{+}$ cells/field and the number of Hoechst ${ }^{+}$cells/field at D0, counted as described above. Changes in mRNA levels were compared using a one-way ANOVA and a Bonferroni's Multiple Comparison Post Test. Analysis of the effects of time (D0 vs D2) and treatment (control vs Wnt5a) was performed using a two-way ANOVA and Bonferroni's Multiple Comparison Post Test. All statistical analyses were performed using GraphPad Prism version 4.00 for Windows, GraphPad Software, San Diego California USA, www.graphpad.com. $\mathrm{p}<0.05$ was considered as a statistically significant difference $(*)$, $\mathrm{p}<0.01(* *), \mathrm{p}<0.001(* * *)$. Results in the text and graphs are presented as mean \pm standard error of the mean (s.e.m).

\section{DA release measurements by HPLC}

DA release was measured in D0 and D2 cultures differentiated for 2 weeks in the absence or presence of Wnt5a. Cells were plated on a 12 well plate and incubated in $200 \mu 1$ of $\mathrm{N} 2$ medium supplemented with $56 \mathrm{mM} \mathrm{KCl}$ for $30 \mathrm{~min}$. The media were then collected and stabilized with $20 \mu \mathrm{l}$ of $1 \mathrm{M}$ perchloric acid $\left(\mathrm{HClO}_{4}\right)$ containing $0.05 \%$ sodium metabisulphate $\left(\mathrm{Na}_{2} \mathrm{~S}_{2} \mathrm{O}_{5}\right)$ and $0.01 \%$ disodium EDTA. Samples were stored at $-70^{\circ} \mathrm{C}$ and on the day of analysis, they were centrifuged at $10000 \mathrm{rpm}$ for $10 \mathrm{~min}$ and filtered though minispin filters for additional $3 \mathrm{~min}$ at $10000 \mathrm{rpm}$ before being injected into the HPLC. For each sample, $20 \mu \mathrm{l}$ was injected into the HPLC, which consisted of a LC-20AT pump (Shimadzu), SIL-20A Autosampler (Shimadzu) and C18 reverse phase column (Bio-Rad, Hercules, USA). Detection was via a 3mm VT-03 flow cell with 
glassy carbon working electrode (Antec Leyden) and Decade II Electrochemical Detector (Antec Leyden). The mobile phase consisted of $17 \% \mathrm{v} / \mathrm{v}$ methanol in purified deionized water containing 70mM KH2PO4, 0.5mM EDTA and 8.0mM sulfonic acid, $\mathrm{pH} 3.0$ and was run at a flow rate of $0.5 \mathrm{ml} / \mathrm{min}$. Peaks were processed by the Azur chromatographic software. Concentrations of DA were calculated for each sample.

\section{Electrophysiological characterization of differentiated VMN cultures}

Cells were cultured as described above and allowed to differentiate for 14 days on PDL/laminin coated glass coverslips. Whole cell current-clamp recordings were performed in D2 cultures differentiated for 2 weeks in the absence or presence of Wnt5a (100ng/ml). Recordings were performed using micropipettes that were pulled from flame-polished borosilicate glass to resistances of 4-7 M $\Omega$. The pipette internal solution contained (in mM) 135 K-gluconate, 4 KCl, 2 NaCl, 10 HEPES, 0.2 EGTA, 4 ATP-Mg, 0.3 GTP-Tris, and 14 phosphocreatine-Tris ( $\mathrm{pH} 7.25,280$ mOsm). Intracellular potentials were not corrected for liquid junction potentials. Recordings were conducted at room temperature. A series of hyperpolarizing and depolarizing step currents were injected to measure the intrinsic properties of each neuron. Synaptic activity (excitatory post-synaptic current; EPSC) was examined at resting membrane potentials following these depolarizing steps. Data was collected using the HEKA Elektronik EPC-10, lowpass filtered at $5 \mathrm{kHz}$ and sampled at $20 \mathrm{kHz}$. Patchmaster software (HEKA; Lambrecht, Germany) was used for data acquisition, and analysis was performed using IgorPro software (Wavemetrics; Oregon, USA). 


\section{RESULTS}

\section{hVMN can be expanded in vitro}

We have previously shown that mouse VM neural stem cells/progenitors can be propagated and differentiated into DA neurons in the presence of VM morphogens. However, the capacity of rodent VM neural stem cells/progenitors to generate midbrain DA neurons has also been shown to decrease with passaging (Parish, et al., 2008). Moreover, the ability of VM neural stem cells/progenitors to generate increased numbers of DA neurons in response to morphogen exposure during expansion and differentiation has not been examined.

We first set out to examine whether human VM stem/progenitor cells could be propagated in the presence of FGF2 and typical midbrain developmental signals, such as Shh and FGF8. In our protocol, cells obtained from week 6-9 fetuses were induced to proliferate, serially passaged over a two week period, and differentiated following each passage in order to assess their potential to give rise to DA neurons (Figure 1A). One of our first observations was that expansion of cells derived from the VM was very consistent for every tissue (from one well to another), but quite variable from one tissue sample to another (Figure 1B). In particular we found that large pieces of VM tissue gave rise to a large number of cells $\left(>1.3 \times 10^{6}\right.$, about 2 million cells) after dissociation of the starting material, but did not propagate and died after Passage 1 (red lines in Figure 1B, C). Tissue preparations containing about 1 million cells $\left(0.7-1.3 \times 10^{6}\right.$ cells, grey lines in Figure 1B, C) propagated and reached passage 2 in three out of seven cases, but total cell numbers did not increase compared to the starting preparation (Figure 1C). Finally, in cultures where the dissection of the VM was restrictive and initial cell counts were low $\left(0.2-0.7 \times 10^{6}\right.$ cells $)$, all samples expanded and a 3 -fold 
increase in cell numbers was detected after 2 weeks (Figure 1B,C, black lines, n=6). Linear regression analysis revealed that the number of cells after the second period of proliferation significantly correlated with the initial cell numbers (Figure 1D), but importantly not with the age of the embryo from which the tissue was dissected (Figure 1E). These results show that smaller pieces of tissue with low cell numbers expand better and suggest that restricted dissections of the VM might be advantageous in order to obtain an optimal proliferation of week 6-9 hVM stem/progenitor cells.

Another interesting observation was that the number of cells did not decrease in all of the cultures after one week of proliferation, at passage1 (Figure 1B), as in rodent cultures (Parish et al., 2008). The loss of cells was more apparent in cultures with medium and high initial cell numbers, despite all cell preparations being plated at the same cell density. This may be explained in part by reduced access to nutrients by progenitors in larger pieces of tissue before dissociation, to longer dissociation time and/or to the presence of adjacent cell populations in larger VM preparations, which may either have a deleterious or inhibitory effects on the expansion of VM progenitors. While cultures with high initial number of cells were in continuous decline, or where not able to survive longer than one week in culture, cultures with low initial cell numbers expanded very efficiently after passage 1 (Figure 1B). Thus our findings suggest that a restrictive dissection of the VM, mild tissue dissociation and low initial cell numbers (about 500.000 cells), are preferable for the optimal expansion of human VM tissue from 6-9 weeks old donors. 
To determine the DA differentiation potential of the propagated cultures, cells were plated onto poly-ornithine/laminin-coated plates and treated for four days with survival and differentiation-inducing factors, including BDNF, GDNF, TGF $\beta 3$, ascorbic acid and dibutyryl cAMP. Primary VM tissue-derived cells readily differentiated and gave rise to cells that were immunoreactive for the pan-neuronal marker Tuj1 and for the rate limiting enzyme in the synthesis of dopamine, tyrosine hydroxylase (TH). Differentiation of the original VM starting material (D0) revealed that $65 \%$ of the cells in the culture were $\mathrm{TuJ} 1^{+}$and $6 \% \mathrm{TH}^{+}$(Figure $2 \mathrm{~A}, \mathrm{Ctrl}$ ). $\mathrm{TH}^{+}$cells exhibited typical DA morphology with processes and varicose-like structures. We then examined the effects of Wnt5a on DA differentiation. We used a concentration of $100 \mathrm{ng} / \mathrm{ml}$ of Wnt5a, which we had previously found (Schulte et al, 2005, Bryja et al, 2007) to maximally activate Wnt/PCP signaling while avoiding the toxic effects of Chaps, the detergent and vehicle used to solubilize Wnt5a. However, addition of Wnt5a did not result in any significant increase in the proportion of $\mathrm{TH}^{+}$cells nor in the number of cells per field (Figure 2A and 2D). When passage $1 \mathrm{hVMN}$ cells (expanded for 1 week) were differentiated for 4 days (D1), using the factors described above, abundant expression of Tuj1 and a high number of $\mathrm{TH}^{+}$neurons was detected (Figure 2B). Most notably, when the number of $\mathrm{TH}^{+}$cells/field at D1 was compared to that at D0, a 3-fold increase was detected (Figure 2D), but Wnt5a did not show any significant effect compared to control. Finally, when hVMN cells were passaged twice (expanded for 14 days) and differentiated for 4 days (D2), we found an increase in the number of both $\mathrm{TuJ} 1^{+}$and $\mathrm{TH}^{+}$neurons (Figure 2C). This result indicated that cells expanded for 2 weeks retain their capacity to generate neurons and more specifically the capacity to differentiate into DA neurons. At this stage, treatment with Wnt5a significantly increased the number of $\mathrm{TH}^{+}$neurons per field 3.3-fold compared to control (from $10 \%$ to $33 \%$, Figure 2D). 
To further confirm that cells expanded for 14 days are able to give rise to correctly specified VM DA neurons, we analyzed the expression of several midbrain markers in $\mathrm{P} 2$ and D2 cultures and compared them to their expression in primary hVM tissue by qPCR (Figure 3). Interestingly, P2 cultures did not show any significant difference in the expression levels of $T H, N U R R 1, F O X A 2, L M X 1 A$ and $L M X 1 B$ compared to primary VM tissue, indicating that the expansion of hVM tissue for 2 weeks in the presence of Shh, FGF8 and FGF2 did not significantly alter gene expression (Figure 3 and Supplemental Figure1). However, when P2 cultures were differentiated for 4 days in the presence of survival factors and Wnt5a (D2), the levels of TH and NURR1 increased 70and 10-fold, respectively, compared to hVM tissue (Figure 3A and B). While the levels of expression of FOXA2, $L M X 1 A$ and $L M X 1 B$ showed trends towards an increase, no significant difference was detected between D2 and VM tissue (Figure 3C-E). A significant increase in $T H$ and NURR1 was also detected at D2 compared to $\mathrm{P} 2$, indicating that our protocol allowed efficient differentiation of expanded cultures. In sum, our results indicate that expanded hVMN cultures do not lose their midbrain DA identity and that upon differentiation they increase or maintain the expression of midbrain DA phenotypic markers.

Finally, we demonstrated that VM spheres could be passaged and maintained in a proliferative state beyond two weeks. However, we found that expansion for 3 passages (21 days) in the present culture conditions did not further increase, but rather decreased, the number of $\mathrm{TH}^{+}$cells in the cultures (data not shown). When $\mathrm{P} 3$ spheres were differentiated (D3), they expressed differentiation markers such as TUJ1 and GFAP, and DA-specific markers such as LMX1B, NURR1 and TH (Supplemental Figure 2). These results indicate that despite the lower $\mathrm{TH}^{+}$cell number, expanded $\mathrm{hVMN}$ cultures 
do not lose their regional identity or their capacity to differentiate into midbrain DA neurons.

In summary, the data presented here indicates that, in the present culture conditions, the overall number of midbrain DA neurons in $\mathrm{hVM}$ cultures propagated as neurospheres does not increase beyond passage 2. Moreover, differentiation at this stage (D2) increased, or at least maintained, the expression of all phenotypic ventral midbrain markers examined, compared to hVM tissue. Thus, our experiments indicate that a high number of midbrain DA neurons can be obtained in 18 days, after expansion of hVM tissue for 2 weeks followed by differentiation for 4 days.

The number of human dopaminergic neurons increases after expansion, passage and differentiation.

Our results indicate that hVM tissue can be expanded and differentiated to increase the yield of midbrain $\mathrm{TH}^{+}$DA neurons per human fetal midbrain. This result is in clear contrast with our previous results showing a reduction in the number of $\mathrm{TH}^{+}$cells after passaging and differentiation of rodent VM tissue (Parish, et al., 2008). Our present findings indicate that human progenitors, unlike their rodent counterparts, have a greater capacity to expand and differentiate into DA neurons. We therefore examined the extent to which hVM tissue can be expanded and contribute to an increase in the number of $\mathrm{TH}^{+}$cells when differentiated in the presence of Wnt5a. We found that compared to cells directly differentiated (D0), the differentiation of hVM cells that underwent two rounds of expansion (D2) increased not only the number of $\mathrm{TH}^{+}$cells/field (3-fold in Wnt5a treated cells, Figure 4A,B) but also the percentage of $\mathrm{TH}^{+}$cells in the cell preparation (\% TH/Hoechst) 6-fold (Figure 4C). These results indicate that it is possible 
to increase the total number of $\mathrm{TH}^{+}$midbrain DA neurons derived from one human VM tissue preparation through expansion and differentiation and that Wnt5a plays a key role during differentiation.

\section{Extended differentiation in Wnt5a improves morphological differentiation, marker} expression and functional properties of midbrain DA neurons derived from hVMN.

We next examined whether the cells produced by the method described above continue developing normally and become functional after differentiation for two weeks. We first examined control- or Wnt5a-treated D0, D1 and D2 cultures for morphological maturation, as assessed by the presence of elaborated dendritic trees and axons. Interestingly, features of morphological maturation improved in cells differentiated after passaging, with D2 cultures being more mature than D1, which in turn were more differentiated than D0. In addition of this, Wnt5a treated cultures contained more $\mathrm{TH}^{+}$ cells that exhibited even more elaborate morphologies and longer processes (Figure 5A). Combined, thee results indicated that extended cultivation and passaging in the present conditions is not deleterious, but rather beneficial for DA differentiation and survival. In order to verify the maturity of DA neurons produced at D2, we examined the expression of transcription factors critical for midbrain DA neuron development. In the absence of Wnt5a we found immature progenitors ( $\mathrm{Lmxla}^{+}$; $\mathrm{Nurr}^{-}$; $\mathrm{TH}^{-}$cells), DA neuroblasts $\left(\mathrm{Lmxla}^{+}\right.$; Nurr1 ${ }^{+} \mathrm{TH}^{-}$cells) and midbrain DA neurons $\left(\mathrm{Lmx} 1 \mathrm{a}^{+}\right.$; Nurr1 ${ }^{+}$; $\mathrm{TH}^{+}$cells). Treatment with $\mathrm{Wnt5a}$ decreased the number of immature progenitors and increased the two populations of postmitotic cells, DA neuroblasts $\left(\mathrm{Lmxla}^{+}\right.$; Nurr ${ }^{+}$ cells) and DA neurons $\left(\mathrm{TH}^{+} ; \mathrm{Nurr}^{+} ; \mathrm{Lmxla}^{+}\right.$cells) (Figure 5B). Thus, our results indicate that Wnt5a increases the number of DA neurons in the cultures by enhancing 
the differentiation of VM DA progenitors into postmitotic neuroblasts and midbrain DA neurons.

In order to assess neuronal functionality, we first examined DA release in D0 and D2 cultures differentiated in the absence or the presence of Wnt5a for two weeks. We first found that DA release was below detection in D0 cultures differentiated without Wnt5a, but it was readily detected in D2 cultures treated with Wnt5a. Although there was a trend for increased DA release with extended cultivation (D0 vs D2 cultures), we only found a significant difference between control and Wnt5a treated cultures, indicating that exposure to Wnt5a improves DA release (Figure 5C). These results also show that extensive culturing does not impair the functionality of DA neurons, as assessed by DA release. We next examined the electrophysiological maturity of neurons in the culture by performing whole-cell patch clamp recordings, targeting cells with a neuronal morphology. Both control and Wnt5a treated neurons exhibited a hyperpolarized resting membrane potential, which was slightly lower and less variable in treated cells $(-44.7$ $\pm 2.8 \mathrm{mV} ; \mathrm{n}=6)$ compared to control cells $(-40.8 \pm 6.1 \mathrm{mV} ; \mathrm{n}=5)$. In both conditions, neurons exhibited spikelets and clear sub-threshold oscillations in response to depolarization (Figure 5D; top trace). Spikelets were larger in amplitude for Wnt5a treated cells compared to control cells (Figure 5E; $p=0.084$ ). Additionally, we could observe neurons in Wnt5a treated cultures firing multiple spikes with more mature phenotypes (Fig 5D; lower trace), which was never seen in control conditions. We analyzed the recurrent network activity in the cultures by quantifying the frequency of EPSCs on the recorded cells at resting membrane potential. Interestingly we found a marked increase of excitatory input onto the Wnt5a treated cells (Fig 5F; $p=0.004$ ). In sum, these results indicate that Wnt5a treated cultures are more mature and active than control cultures differentiated in the absence of Wnt5a. 
In summary, our results show that expansion of human VM tissue for 2 weeks followed by differentiation in the presence or absence of Wnt5a produces cultures containing large numbers of DA neurons. Moreover, we found that Wnt5a treatment during differentiation resulted in cultures exhibiting improved neuronal morphological differentiation (greater maturity of dendritic arbors and axons) with appropriate electrophysiological properties; increased differentiation of progenitors into postmitotic neuroblasts, increased number of midbrain DA neurons and increased DA release.

\section{DISCUSSION}

Human fetal ventral midbrain (hVM) is a well known but a limited source of DA neurons for CRT in Parkinson's disease. We now show that is possible to expand hVM progenitors as neurospheres (hVMN) for several passages and that an optimal 3-fold expansion of $\mathrm{hVMN}$ cells can be achieved after 2 passages and culture for 2 weeks in proliferating and VM patterning conditions. We also found that the combination of 2 weeks of expansion and 4 day differentiation of hVMN in the presence of Wnt5a leads to a 3.3-fold increase in DA cell density $\left(\mathrm{TH}^{+}\right.$cells/area), compared to unexpanded cells differentiated for 4 days without Wnt5a. Consistent with an increase in TH cell density (x3.3) and the total number of cells (x3), we found that expansion and differentiation of 1 human VM produced a 6-fold increase in the total number of $\mathrm{TH}^{+}$cells, compared to cells directly differentiated for 4 days in the absence of Wnt5a. This result is clearly different from that previously obtained with rodent VMN, which did not expand (Parish et al., 2009). The different behavior of $\mathrm{hVMN}$ compared to rodent VMN might reflect species differences either in the intrinsic properties of VM progenitors or in their extrinsic factor requirements. We conclude that $\mathrm{hVMN}$, unlike rodent VMN cultures, 
can significantly expand and increase the total number of $\mathrm{TH}^{+}$cells obtained from 1 $\mathrm{VM}$, and as such is an attractive source of $\mathrm{TH}^{+}$cells.

Our results show that the use of appropriate midbrain-specific cell extrinsic factors, including morphogens, mitogens and growth factors that control midbrain DA progenitor identity, expansion and differentiation, improves the efficiency of the generation of midbrain DA neurons derived from hVM tissue. Our study differs from previous reports in that we expanded DA progenitors in the presence of a combination of factors used in midbrain specification and DA differentiation of embryonic stem cells (Shh, FGF8 and FGF2), instead of FGF2 and EGF, the classical forebrain neurosphere culture conditions. We hypothesize that by providing region-specific instructive signals to proliferating VM progenitors, these cells retain their capacity to continue generating midbrain DA neurons. Finally, our study differs from previous studies in the use of Wnt5a for the efficient differentiation of human DA precursors into $\mathrm{TH}^{+}$midbrain DA neurons. Interestingly, clear effects of Wnt5a were only detected upon differentiation after the second passage, when cell preparations were more homogeneous. Our results also indicate that cell preparations differentiated after two passages yield the greatest number of $\mathrm{TH}^{+}$cells that can be obtained from one VM tissue. This increase in the number of midbrain DA neurons per hVM is of such a magnitude that it could allow for a significant reduction in the amount of donor VM tissue required to treat PD patients if this was to taken forward to the clinic. Moreover, since extended differentiation of such cultures for two weeks in the presence of Wnt5a resulted in cell reparations that acquired remarkable morphological maturity, expression of specific midbrain markers, improved electrophysiological properties and enhanced DA release, our results suggest that these cells could be good candidates for transplantation. The number of DA neurons necessary to elicit a functional recovery in PD patients has been estimated to be 
around 100,000 cells (Kordower et al., 1995). We hereby show that our method increases an initial population of about $30,000 \mathrm{TH}^{+}$cells $\left(6 \% \mathrm{TH}^{+}\right.$cells of 500,000 cells in a human VM) by 6-fold, a number 1.8 times greater than the number of DA neurons present in the human adult substantia nigra $(100,000$ cells in the SNpc, Damier et al, 1999). Thus, our procedure might allow for the complete grafting of one side of the PD patient's brain using tissue from only one single donor. Clearly, several variables need to be defined and further refinements are needed before cells obtained by this method can be used clinically in such a capacity. We know, for instance, that Wnt5a promotes DA neuritogenesis (Blakely et al., 2011, current observations), which may compromise the transplantability of the DA neurons. Future studies should thus focus on identifying how long Wnt5a exposure should last (to avoid excessive outgrowth) as well as on testing the capacity of $\mathrm{hVMN}$ derived-DA neurons to survive and functionally engraft in animal models of PD.

In conclusion, hVM tissue grown in the presence of developmentally relevant factors, such as Shh, FGF8 and Wnt5a, offers an efficient in vitro DA cell preparation protocol that may find an application in future CRT for PD patients. 


\section{ACKNOWLEDGEMENTS}

We would like to thank to all members of the Arenas group for fruitful discussions, to Johny Söderlund and Pam Tyers for technical support and Alessandra Nani for secretarial assistance. This work was supported by grants from the Swedish Research Council (VR2008:2811, VR2008:3287 and DBRM), Karolinska Institutet, Parkinsonfonden, German Parkinson Foundation (dPV), National Helth and Medical Research council Australia (NHMRC) and the European Commission under the 7th Framework Programme -HEALTH- Collaborative Projects: NeuroStemcell (European Consortium for Stem Cell Therapy in Neurodegenerative Diseases) and Transeuro (Contractn ${ }^{\circ}$ 242003). DR was supported by the Foundation for Science and Technology from the Portuguese Government (SFRH/BD/24585/2005). CLP was supported by an National health and medical research council, Australia (NHMRC) CJ Martin training fellowship and an NHMRC career development award and Viertel senior medical research fellowship, Australia. 


\section{REFERENCES}

1. Barberi, T., Klivenyi, P., Calingasan, N. Y., Lee, H., Kawamata, H., Loonam, K., Perrier, A. L., Bruses, J., Rubio, M. E., Topf, N., Tabar, V., Harrison, N. L., Beal, M. F., Moore, M. A. S., and Studer, L., 2003. Neural subtype specification of fertilization and nuclear transfer embryonic stem cells and application in parkinsonian mice. Nature Biotechnology 21, 1200-1207.

2. Bjorklund, A., Dunnett, S. B., Brundin, P., Stoessl, A. J., Freed, C. R., Breeze, R. E., Levivier, M., Peschanski, M., Studer, L., and Barker, R., 2003. Neural transplantation for the treatment of Parkinson's disease. Lancet Neurology 2, 437-445.

3. Blakely BD., Bye CR., Fernando CV., Horne MK., Macheda ML., Stacker, S.A., Arenas, E., and Parish, C. L., 2011. Wnt5a Regulates Midbrain Dopaminergic Axon Growth and Guidance. PLoS ONE 6(3): e18373. doi:10.1371/journal.pone.0018373

4. Bryja, V., Schulte, G., Rawal, N., Grahn, A. and Arenas, E., 2007. Wnt-5a induces Dishevelled phosphorylation and dopaminergic differentiation via a CK1-dependent mechanism, Journal of Cell Science 120: 586-595

5. Courtois, E. T., Castillo, C. G., Seiz, E. G., Ramos, M., Bueno, C., Liste, I., and MartinezSerrano, A., 2010. In Vitro and in Vivo Enhanced Generation of Human A9 Dopamine Neurons from Neural Stem Cells by Bcl-X-L. Journal of Biological Chemistry 285, 98819897.

6. Damier, P., Hirsch, E.C, Agid, Y., Graybiel, A.M., 1999. The substantia nigra of the human brain. I. Nigrosomes and the nigral matrix, a compartmental organization based on calbindin $\mathrm{D}(28 \mathrm{~K})$ immunohistochemistry. Brain 122 (8): 1421-1436.

7. Donato, R., Miljan, E. A., Hines, S. J., Aouabdi, S., Pollock, K., Patel, S., Edwards, F. A., and Sinden, J. D., 2007. Differential development of neuronal physiological responsiveness in two human neural stem cell lines. Bmc Neuroscience 8.

8. Freed, C. R., Greene, P. E., Breeze, R. E., Tsai, W. Y., DuMouchel, W., Kao, R., Dillon, S., Winfield, H., Culver, S., Trojanowski, J. Q., Eidelberg, D., and Fahn, S., 2001. Transplantation of embryonic dopamine neurons for severe Parkinson's disease. New England Journal of Medicine 344, 710-719.

9. Hargus, G., Cooper, O., Deleidi, M., Levy, A., Lee, K., Marlow, E., Yow, A., Soldner, F., Hockemeyer, D., Hallett, P. J., Osborn, T., Jaenisch, R., and Isacson, O., 2010. Differentiated Parkinson patient-derived induced pluripotent stem cells grow in the adult rodent brain and reduce motor asymmetry in Parkinsonian rats. Proceedings of the National Academy of Sciences of the United States of America 107, 15921-15926.

10. Hovakimyan, M., Haas, S. J. P., Schmitt, O., Gerber, B., Wree, A., and Andressen, C., 2006. Mesencephalic human neural progenitor cells transplanted into the neonatal hemiparkinsonian rat striatum differentiate into neurons and improve motor behaviour. Journal of Anatomy 209, 721-732.

11. Inestrosa, N. C., and Arenas, E., 2010. Emerging roles of Wnts in the adult nervous system. Nature Reviews Neuroscience 11, 77-86.

12. Jin, G. H., Tan, X. F., Tian, M. L., Qin, J. B., Zhu, H. X., Huang, Z., and Xu, H. J., 2005. The controlled differentiation of human neural stem cells into $\mathrm{TH}$-immunoreactive (ir) neurons in vitro. Neuroscience Letters 386, 105-110.

13. Kawasaki, H., Mizuseki, K., Nishikawa, S., Kaneko, S., Kuwana, Y., Nakanishi, S., and Sasai, Y., 2000. Induction of midbrain dopaminergic neurons from ES cells by stromal cell-derived inducing activity. Neuron 28, 31-40.

14. Kim, J. H., Auerbach, J. M., Rodriguez-Gomez, J. A., Velasco, I., Gavin, D., Lumelsky, N., Lee, S. H., Nguyen, J., Sanchez-Pernaute, R., Bankiewicz, K., and McKay, R., 2002. 
Dopamine neurons derived from embryonic stem cells function in an animal model of Parkinson's disease. Nature 418, 50-56.

15. Kordower, J. H., Freeman, T. B., Snow, B. J., Vingerhoets, F. J. G., Mufson, E. J., Sanberg, P. R., Hauser, R. A., Smith, D. A., Nauert, G. M., Perl, D. P., and Olanow, C. W., 1995. Neuropathological evidence of graft-survival and striatal reinnervation after the transplantation of fetal mesencephalic tissue in a patient with Parkinson's disease. New England Journal of Medicine 332, 1118-1124.

16. Kriks, S., Shim, J. W., Piao, J. H., Ganat, Y. M., Wakeman, D. R., Xie, Z., Carrillo-Reid, L., Auyeung, G., Antonacci, C., Buch, A., Yang, L. C., Beal, M. F., Surmeier, D. J., Kordower, J. H., Tabar, V., and Studer, L., 2011. Dopamine neurons derived from human ES cells efficiently engraft in animal models of Parkinson's disease. Nature 480, 547-U177.

17. Lee, S. H., Lumelsky, N., Studer, L., Auerbach, J. M., and McKay, R. D., 2000. Efficient generation of midbrain and hindbrain neurons from mouse embryonic stem cells. Nature Biotechnology 18, 675-679.

18. Lotharius, J., Barg, S., Wiekop, P., Lundberg, C., Raymon, H. K., and Brundin, P., 2002. Effect of mutant alpha-synuclein on dopamine homeostasis in a new human mesencephalic cell line. Journal of Biological Chemistry 277, 38884-38894.

19. Maciaczyk, J., Singec, Y., Maciaczyk, D., and Nikkhah, G., 2008. Combined use of BDNF, ascorbic acid, low oxygen, and prolonged differentiation time generates tyrosine hydroxylase-expressing neurons after long-term in vitro expansion of human fetal midbrain precursor cells. Experimental Neurology 213, 354-362.

20. Mendez, I., Sanchez-Pernaute, R., Cooper, O., Vinuela, A., Ferrari, D., Bjorklund, L., Dagher, A., and Isacson, O., 2005. Cell type analysis of functional fetal dopamine cell suspension transplants in the striatum and substantia nigra of patients with Parkinson's disease. Brain 128, 1498-1510.

21. Milosevic, J., Brandt, A., Roemuss, U., Arnold, A., Wegner, F., Schwarz, S. C., Storch, A., Zimmermann, H., and Schwarz, J., 2006. Uracil nucleotides stimulate human neural precursor cell proliferation and dopaminergic differentiation: involvement of MEK/ERK signalling. Journal of Neurochemistry 99, 913-923.

22. Olanow, C. W., Goetz, C. G., Kordower, J. H., Stoessl, A. J., Sossi, V., Brin, M. F., Shannon, K. M., Nauert, G. M., Perl, D. P., Godbold, J., and Freeman, T. B., 2003. A double-blind controlled trial of bilateral fetal nigral transplantation in Parkinson's disease. Annals of Neurology 54, 403-414.

23. Parish, C. L., Castelo-Branco, G., Rawal, N., Tonnesen, J., Sorensen, A. T., Salto, C., Kokaia, M., Lindvall, O., and Arenas, E., 2008. Wnt5a-treated midbrain neural stem cells improve dopamine cell replacement therapy in parkinsonian mice. Journal of Clinical Investigation 118, 149-160.

24. Piccini, P., Brooks, D. J., Bjorklund, A., Gunn, R. N., Grasby, P. M., Rimoldi, O., Brundin, P., Hagell, P., Rehncrona, S., Widner, H., and Lindvall, O., 1999. Dopamine release from nigral transplants visualized in vivo in a Parkinson's patient. Nature Neuroscience 2, 1137-1140.

25. Politis, M., Wu, K., Loane, C., Quinn, N. P., Brooks, D. J., Rehncrona, S., Bjorklund, A., Lindvall, O., and Piccini, P., 2010. Serotonergic Neurons Mediate Dyskinesia Side Effects in Parkinson's Patients with Neural Transplants. Science Translational Medicine 2.

26. Rawal, N., Castelo-Branco, G., Sousa, K. M., Kele, J., Kobayashi, K., Okano, H., and Arenas, E., 2006. Dynamic temporal and cell type-specific expression of Wnt signaling components in the developing midbrain. Experimental Cell Research 312, 1626-1636.

27. Roy, N. S., Cleren, C., Singh, S. K., Yang, L., Beal, M. F., and Goldman, S. A., 2006. Functional engraftment of human ES cell-derived dopaminergic neurons enriched by coculture with telomerase-immortalized midbrain astrocytes. Nature Medicine 12, 1259-1268. 
28. Sanchez-Pernaute, R., Studer, L., Bankiewicz, K. S., Major, E. O., and McKay, R. D. G., 2001. In vitro generation and transplantation of precursor-derived human dopamine neurons. Journal of Neuroscience Research 65, 284-288.

29 Sanchez-Pernaute, R., Lee, H., Patterson, M., Reske-Nielsen, C., Yoshizaki, T., Sonntag, K. C., Studer, L., and Isacson, O., 2008. Parthenogenetic dopamine neurons from primate embryonic stem cells restore function in experimental Parkinsons disease. Brain 131, 2127-2139

30. Schulte, G., Bryja, V., Rawal, N., Castelo-Branco, G., Sousa, K. M. and Arenas, E., 2005. Purified Wnt-5a increases differentiation of midbrain dopaminergic cells and dishevelled phosphorylation, Journal of Neurochemistry 92(6): 1550-1553.

31. Sonntag, K. C., Pruszak, J., Yoshizaki, T., van Arensbergen, J., Sanchez-Pernaute, R., and Isacson, O., 2007. Enhanced yield of neuroepithelial precursors and midbrain-like dopaminergic neurons from human embryonic stem cells using the bone morphogenic protein antagonist Noggin. Stem Cells 25, 411-418.

32. Storch, A., Paul, G., Csete, M., Boehm, B. O., Carvey, P. M., Kupsch, A., and Schwarz, J., 2001. Long-term proliferation and dopaminergic differentiation of human mesencephalic neural precursor cells. Experimental Neurology 170, 317-325.

33. Villa, A., Liste, I., Courtois, E. T., Seiz, E. G., Ramos, M., Meyer, M., Juliusson, B., Kusk, P., and Martinez-Serrano, A., 2009. Generation and properties of a new human ventral mesencephalic neural stem cell line. Experimental Cell Research 315, 1860-1874.

34. Wang, X., Li, X. X., Wang, K., Zhou, H. F., Xue, B., Li, L. S., and Wang, X. M., 2004. Forskolin cooperating with growth factor on generation of dopaminergic neurons from human fetal mesencephalic neural progenitor cells. Neuroscience Letters 362, 117121.

35. Wernig, M., Zhao, J. P., Pruszak, J., Hedlund, E., Fu, D. D., Soldner, F., Broccoli, V., Constantine-Paton, M., Isacson, O., and Jaenisch, R., 2008. Neurons derived from reprogrammed fibroblasts functionally integrate into the fetal brain and improve symptoms of rats with Parkinson's disease. Proceedings of the National Academy of Sciences of the United States of America 105, 5856-5861.

36. Winkler, C., Kirik, D., and Bjorklund, A., 2005. Cell transplantation in Parkinson's disease: how can we make it work? Trends in Neurosciences 28, 86-92. 


\section{FIGURE LEGENDS}

Figure 1: $\boldsymbol{h} V M N$ expansion in vitro. (A) Experimental design. Human VM fetal tissue was dissociated into a single-cell suspension, referred to as starting material, and subsequently cultured to promote proliferation (P0) or differentiation (D0). After one week, expanding cultures formed spheres. Half the VMN were passaged (P1) and the remainder plated for differentiation (D1). P1 cells were induced to proliferate for a further 7 days (P2) and plated for final differentiation (D2). Proliferation was performed in the presence of Shh, FGF8, FGF2 and BDNF, and differentiation in the presence of ascorbic acid, BDNF, GDNF, TGF $\beta$, db-cAMP and Wnt5a. (B) Graph representing the number of cells in the starting material and at passage 1 and 2. Each line depicts an independent VM culture. Expansion of large pieces of hVM issue, which contained a high initial number of cells (red lines), and some of the preparations with medium cell numbers (grey lines) yielded no surviving cells at passage 2 (no value represented at P2). Surprisingly, restricted dissections gave rise to starting preparations with low cell numbers (approximately 200,000 to 700,000 cells, black lines) that expanded remarkably well and lead to a 3 fold increase in cell numbers after the second period of proliferation (day 14, 1,500.000 cells). (C) Individual cultures were grouped according to the yield after tissue dissociation into low (around 500,000 cells, black lines), medium (around 1,000.000 cells, grey lines) or high (around 2,000.000 cells, red lines). In preparations with low cells numbers there was a 3-fold increase in cell numbers after 2 weeks in proliferation conditions, whilst medium and high preparations did not expand well. Low: N=6, SM- $0.462 \pm 0.070 ;$ P1- $1.023 \pm 0.2830 ;$ P2- $1.429 \pm 0.156$. Medium: $\mathrm{N}=7$, SM- $1.024 \pm 0.055 ; \mathrm{P} 1-0.670 \pm 0.295 ; \mathrm{P} 2-0.301 \pm 0.208$. High: $\mathrm{N}=2$, SM- $2.115 \pm 0.115 ;$ P1- $0.1725 \pm 0.072 ;$ P2- 0). (C) Linear regression analysis confirmed that the expansion of cells derived from the VM was highly dependent on the 
numbers of cells after dissociation $\left(\mathrm{r}^{2}=0.4127, \mathrm{~N}=15, \mathrm{p}=0.0098^{* *}\right)$, but not on the age of the embryo (D) $\left(\mathrm{r}^{2}=0.020, \mathrm{~N}=15, \mathrm{p}=0.770\right)$.

Figure 2: Dopaminergic differentiation potential of hVMN following serial passaging. (A) A large number of Tuj1 and $\mathrm{TH}^{+}$cells were found at D0. Wnt5a treatment did not promote a significant increase in the numbers of $\mathrm{TH}^{+}$cells counted per field (TH/Field- Ctrl: $10.23 \pm 3.276$, Wnt5a: $10.64 \pm 1.869, \mathrm{~N}=9$ ). (B) After 7 days of proliferation, differentiated neurospheres contained a high number of Tuj1 and $\mathrm{TH}^{+}$ cells, but did not appear to be significantly influenced by the presence of Wnt5a (Ctrl: 21.78 \pm 13.77, Wnt5a: $31.45 \pm 18.43 \mathrm{~N}=4$ ). (C) After 2 weeks of expansion, high numbers of $\mathrm{TuJ}^{+}$and $\mathrm{TH}^{+}$neurons were still observed. (D) At this stage, Wnt5a treatment significantly increased the number of $\mathrm{TH}^{+}$cells per field $(\mathbf{C t r l}: 17.03 \pm 7.715$; Wnt5a: $33.40 \pm 8.664, N=6, p=0.0108^{*}$ paired t-test). Scale bars $=50 \mu \mathrm{m}$ for left and middle column micrographs; $25 \mu \mathrm{m}$ for pictures in right hand column.

\section{Figure 3: Figure 3: Expression of VM DA markers in expanding and differentiating} human ventral midbrain cultures. (A-E) qPCR analysis revealed that the hVM derived cells retained or increased the expression of VM-specific markers after passaging (P2) and differentiation (D2), compared to starting material. Statistical analysis was performed using a one-way ANOVA and Bonferroni's post hoc test. ${ }^{*} \mathrm{p}<0.05,{ }^{* *} \mathrm{p}<0.01$; $\mathrm{n}=3-4$ independent cultures per condition. 
Figure 4: Propagation and differentiation of human VM progenitors expands the number of midbrain $\mathbf{T H}^{+} \mathrm{DA}$ neurons 6-fold. (A) The number of $\mathrm{TH}^{+}$cells in the starting cell preparation, differentiated in the presence of Wnt5a (D0), was compared with cells propagated for two weeks and differentiated in the presence of Wnt5a. (B) A 3-fold increase was detected in the number of $\mathrm{TH}^{+}$cells/field (Do: $10.64 \pm 1.869 \mathrm{~N}=9$; D2: $33.67 \pm 7.328 \mathrm{~N}=7, \mathrm{p}=0.0042^{* *}$, unpaired t-test). Scale bars $=50 \mu \mathrm{m}$ for $20 \mathrm{x}$ pictures, $25 \mu \mathrm{m}$ for $20 \mathrm{x}$ pictures. (C) The percentage of $\mathrm{TH}^{+}$cells out of the total $(\%$ $\mathrm{TH}^{+} /$Hoechst ${ }^{+}$cells) increased by 6-fold when control D0 and Wnt5a D2 were compared (* $\mathrm{p}<0.05$ by two-way ANOVA and Tukey's post hoc test), indicating that our expansion and differentiation protocol effectively increases the number of $\mathrm{TH}^{+}$cells that can be obtained from 1 human VM tissue.

Figure 5: Extended differentiation and Wnt5a treatment improve morphological differentiation, marker expression and the functional properties of $h V M N$-derived DA neurons. (A) Morphological differentiation improved with passaging as assessed by elaborated morphologies and longer processes in D2 and D1 cultures when compared to D0. Differentiation was further increased by Wnt5a treatment. (B) D2 cultures contained DA immature DA progenitors $\left(\mathrm{Lmxla}^{+}\right.$; Nurr1 ${ }^{-}$; $\mathrm{TH}^{-}$cells), DA neuroblasts $\left(\mathrm{Lmxla}^{+} ; \mathrm{Nurr}^{+} ; \mathrm{TH}^{-}\right.$cells) and DA neurons $\left(\mathrm{Lmx} 1 \mathrm{a}^{+} ; \mathrm{Nurr}^{+} ; \mathrm{TH}^{+}\right.$cells). Wnt5a treatment enhanced differentiation by increasing the number of DA neuroblasts and DA neurons and decreasing the number of immature DA progenitors. (C) Extensive culturing does not impair the functionality of the DA neurons, as assessed by DA release, which was further enhanced by Wnt5a treatment (Ctrl vs Wnt5a: U=4.00, $\mathrm{p}=0.0373^{*}$, Mann Whitney U test, one-tailed). (D) D2 neurons exhibit 
electrophysiological properties of mature neurons such as a hyperpolarized resting membrane potential, spikelets and clear sub-threshold oscillations in response to depolarization. Wnt5a-treated cultures were more mature and active, as assessed by (E) larger spikelet amplitudes and (F) increased frequency of EPSCs $(\mathrm{p}=0.004 * *)$. 
Figure 1

A

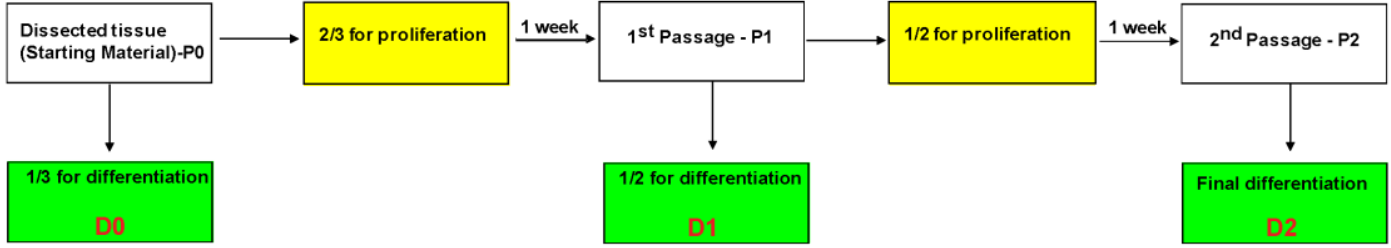

B

C
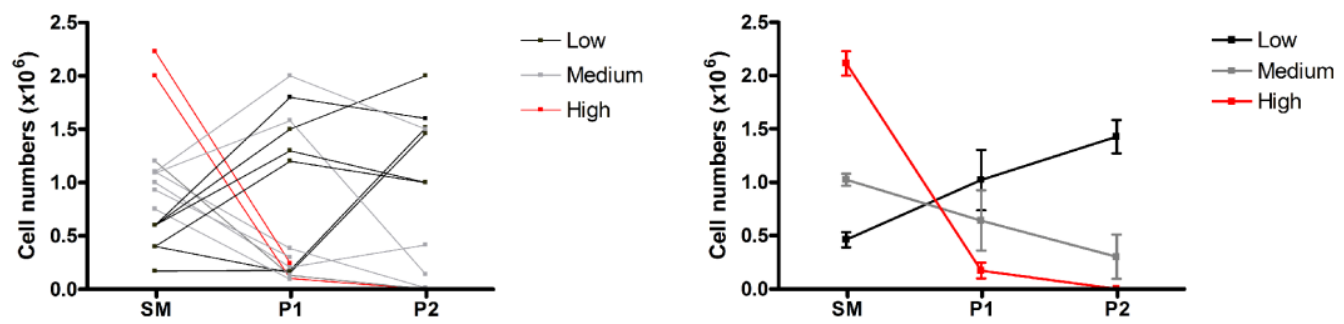

D

E
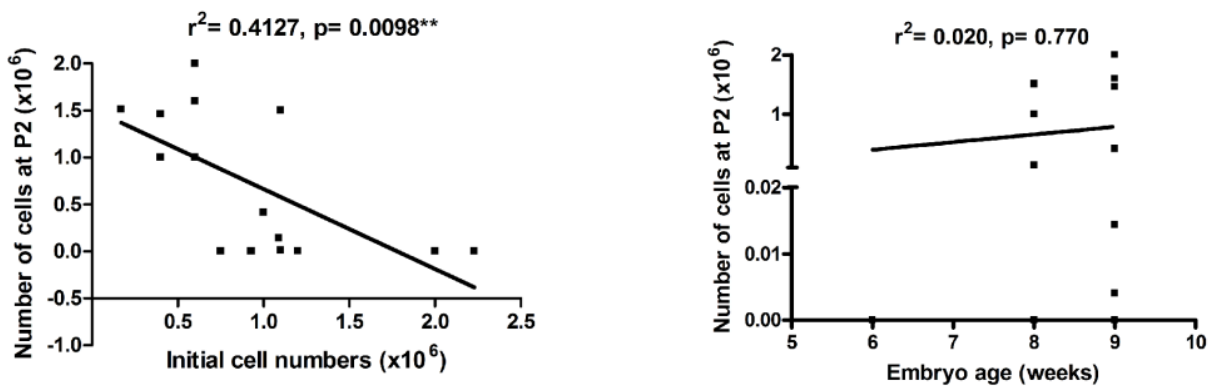
Figure 2
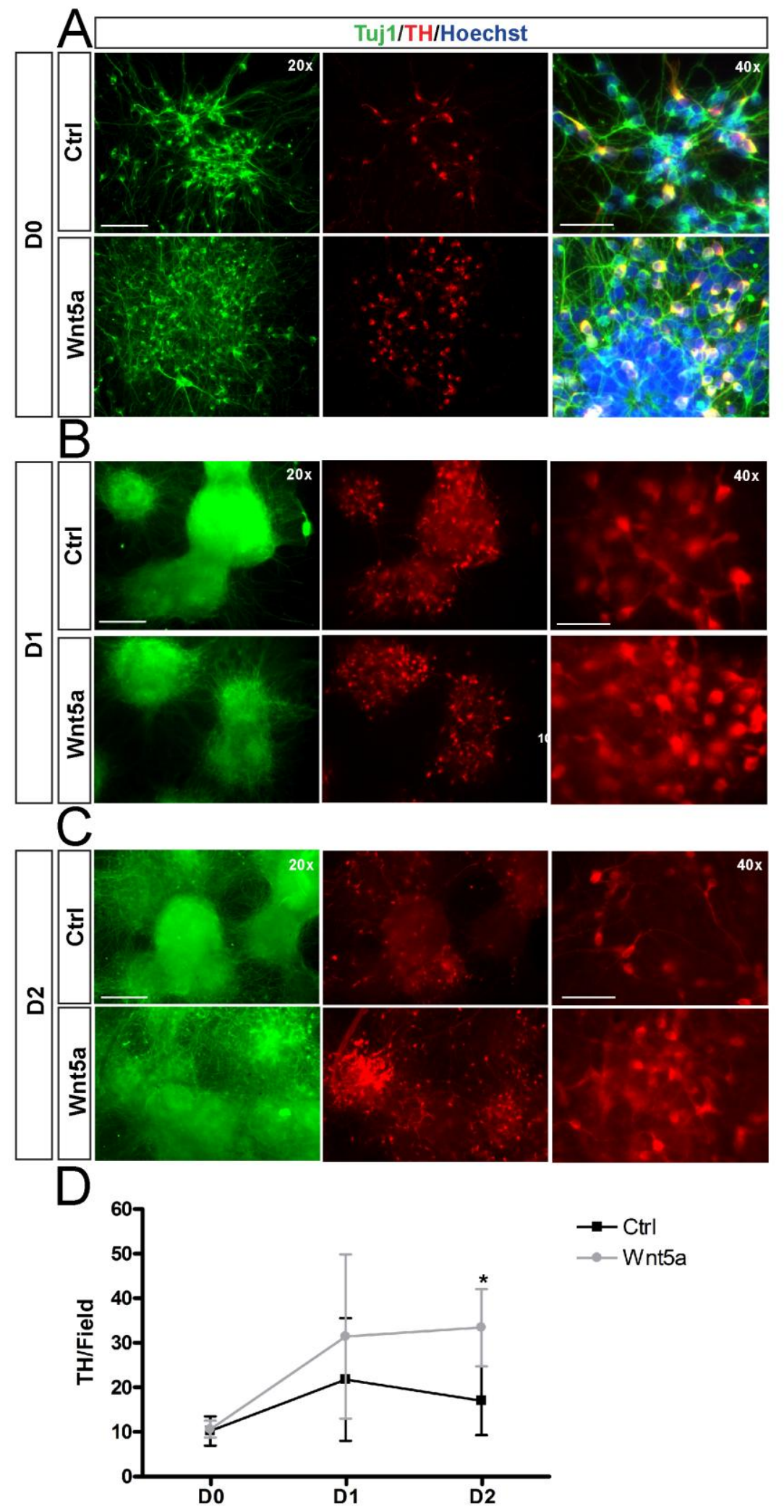
Figure 3

A

B

TH
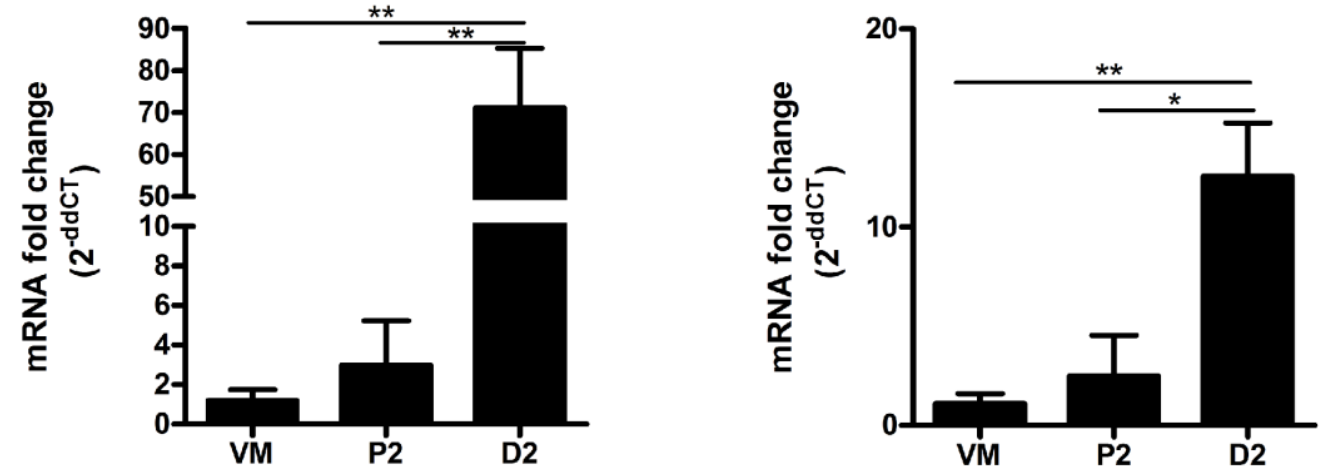

C

Foxa2

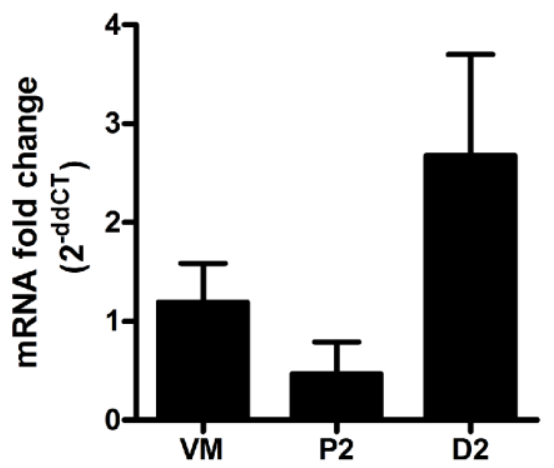

D

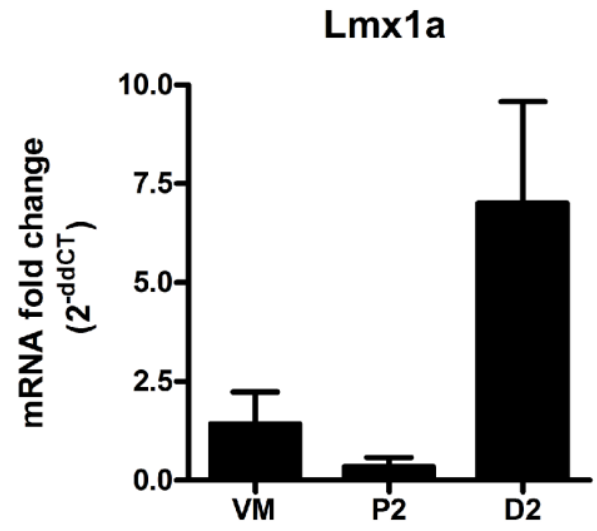

E

Lmx1b

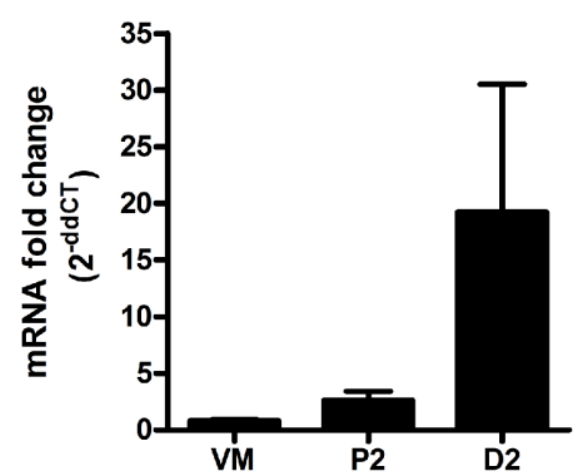


Figure 4
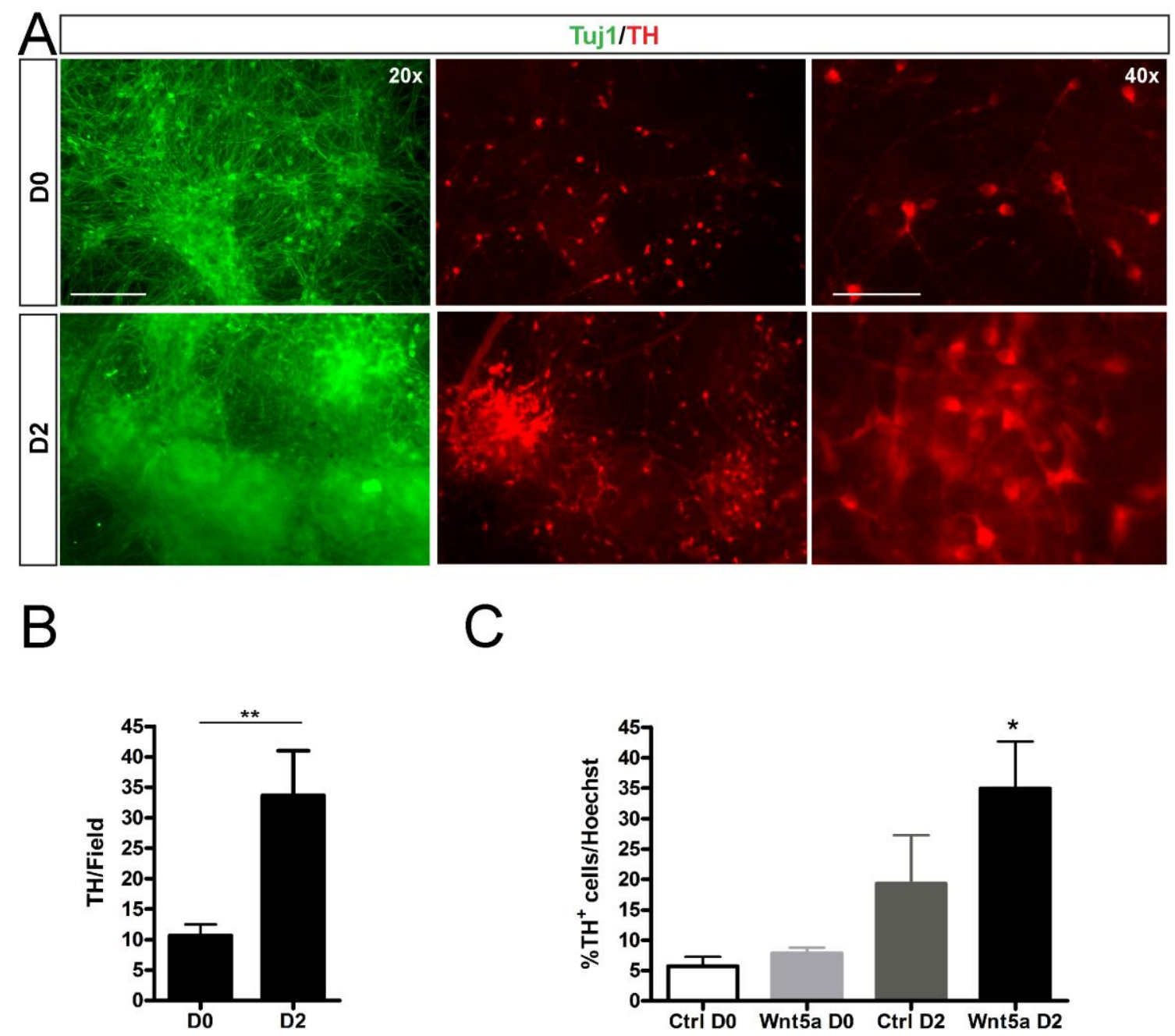
Figure 5
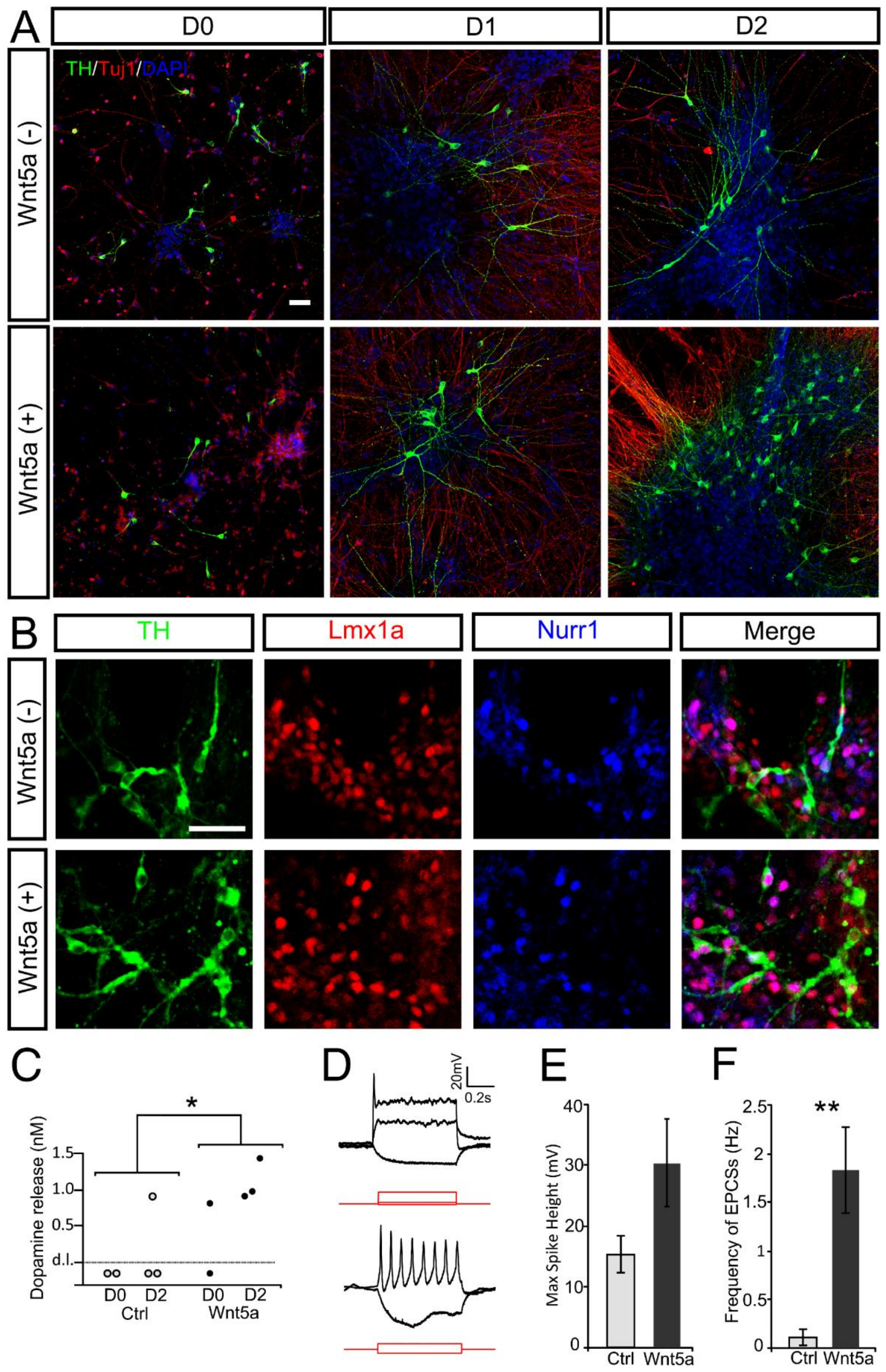


\section{HIGHLIGHTS}

- We present a method to increase the yield of human midbrain dopaminergic neurons

- Human ventral midbrain neural stem/progenitor cells can be expanded 3 fold

- Expanded cells retain their capacity to differentiate into dopaminergic neurons

- Wnt5a enhances the differentiation of human ventral midbrain progenitors into mature dopaminergic neurons

- After expansion and differentiation, cell preparations can contain 6-fold more midbrain dopaminergic neurons than the starting ventral midbrain preparation 


\section{University Library}

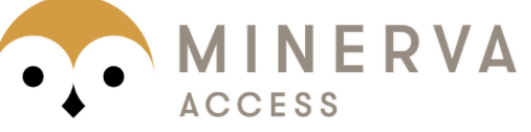

A gateway to Melbourne's research publications

Minerva Access is the Institutional Repository of The University of Melbourne

\section{Author/s:}

Ribeiro, D;Goya, RL;Ravindran, G;Vuono, R;Parish, CL;Foldi, C;Piroth, T;Yang, S;Parmar, M;Nikkhah, G;Hjerling-Leffler, J;Lindvall, O;Barker, RA;Arenas, E

Title:

Efficient expansion and dopaminergic differentiation of human fetal ventral midbrain neural stem cells by midbrain morphogens

Date:

2013-01-01

Citation:

Ribeiro, D., Goya, R. L., Ravindran, G., Vuono, R., Parish, C. L., Foldi, C., Piroth, T., Yang, S., Parmar, M., Nikkhah, G., Hjerling-Leffler, J., Lindvall, O., Barker, R. A. \& Arenas, E. (2013). Efficient expansion and dopaminergic differentiation of human fetal ventral midbrain neural stem cells by midbrain morphogens. NEUROBIOLOGY OF DISEASE, 49 (1), pp.118-127. https://doi.org/10.1016/j.nbd.2012.08.006.

\section{Publication Status:}

Accepted manuscript

Persistent Link:

http://hdl.handle.net/11343/41837 